\title{
UM RELATO DE SI EM ESSE CABELO, DE DJAIMILIA PEREIRA DE ALMEIDA: O CORPO COMO OBJETO DE VIOLÊNCIA ÉTICA
}

\section{A REPORT OF ONESELF IN ESSE CABELO, BY DJAIMILIA PEREIRA DE ALMEIDA: THE BODY AS AN OBJECT OF ETHICAL VIOLENCE}

\author{
Shaianna da Costa Araújo" \\ Algemira de Macedo Mendes**
}

Resumo: No presente trabalho, analisaremos a obra Esse Cabelo (2015), da escritora angolana Djaimilia Pereira de Almeida, à luz das categorias propostas por Butler (2015) no que se refere ao ato de relatar a si. Situaremos a obra no contexto da escrita de si e do relato de si, discutindo as noções de autoria colocadas por Foucault (2001). Discorreremos sobre a transmutação da estética em moral, demonstrando como essa metamorfose se manifesta na obra analisada, e ainda verificando de que forma o corpo, enquanto objeto de padrões estéticos, pode se tornar vítima da violência ética. Trabalharemos a hipótese de que esse corpo negro, entendido como ferramenta política de compreensão do mundo, é um potencial objeto da violência descrita por Butler, à medida que também se submete às pretensões morais da universalidade.

Palavras-chave: Esse Cabelo; relatar a si; cabelo crespo.

AвSTRACT: In this paper, we will analyze the work Esse Cabelo (2015), by the Angolan writer Djaimilia Pereira de Almeida, in the light of the categories proposed by Butler (2015) regarding the act of reporting oneself. We will situate the work in the context of selfwriting and self-reporting, discussing the notions of authorship proposed by Focault (2001). We will discuss the transmutation of aesthetics into morals, demonstrating how this metamorphosis manifests itself in the analysed work, verifying how the body, as an object of aesthetic standards, might become a victim of ethical violence.

\footnotetext{
"Graduada em Comunicação Social com Habilitação em Jornalismo pelo Universidade Federal do Piauí. Pós-graduada em Comunicação Organizacional pela Universidade Estácio de Sá. Mestranda em Letras pela Universidade Estadual do Piauí. E-mail: shaiaraujo7@gmail.com.

"*t" Graduada em Letras pela Universidade Estadual do Piauí. Mestre em Teoria Literária pela Universidade Federal de Pernambuco. Doutora em Letras pela Pontifícia Universidade Católica do Rio Grande do Sul. Pós- doutora em Literaturas Africanas de Língua Portuguesa pela Universidade de Lisboa. Professora Associada da Universidade Estadual do Piauí e da Universidade Estadual do Maranhão.E-mail: algemiramendes95@gmail.com.
} 
We will work on the hypothesis that this black body, understood as a political tool for understanding the world, is a potential object of the violence described by Butler, as it also submits to the moral claims of universality.

KEYWORDs: Esse Cabelo; giving account of oneself; curly hair.

\section{INTRODUÇÃO}

A obra literária Esse Cabelo (2015), da escritora angolana Djaimilia Pereira de Almeida, é um romance que reúne elementos ensaísticos e biográficos. Em entrevistas concedidas a veículos de comunicação, a escritora reconhece que seu trabalho foi fortemente influenciado por experiências vividas e inquietações diversas, embora declare não se confundir inteiramente com a protagonista da narrativa. As semelhanças entre criadora e criatura, porém, já partem de seus nomes: a alcunha da personagem - "Mila" - pode ser compreendida como diminutivo ou corruptela de "Djaimilia". Notamos um paralelismo ainda mais aparente se considerarmos as origens da escritora e as de Mila: ambas filhas de mãe angolana e pai português, deixaram a África na primeira infância para viverem nos subúrbios das terras lusitanas. Os marcos temporais também coincidem: nascida em 1982, Djaimilia Pereira de Almeida viveu sua adolescência na década de 1990, mesmo período em que Mila, nas tramas da narrativa, passou por suas experiências de puberdade. Acerca desses fatos, Almeida alega que existe, de fato, uma justaposição permanente entre a história de Mila e a sua, mas que obra e personagem são resultados de um complexo de emoções e intuições advindas de outras pessoas, próximas ou distantes, com histórias que são similares à dela própria ou mesmo muito diferentes (REDE ANGOLA, 2015). A escritora alegou, ainda, que o livro foi escrito menos a partir das narrativas reais do que a partir - e sobretudo - de rumores acerca do passado, que correm em sua família (PERNAMBUCO, 2016). O grupo editorial Leya, que publicou a obra tanto em Portugal quanto no Brasil, classifica o trabalho como "ficção" e "romance autobiográfico" - categorização que inicialmente parece até um tanto contraditória, mas que deixa clara a intercorrência de elementos ficcionais e de aspectos da vida de Djaimilia Pereira de Almeida, o que nos impele a aceitar o caráter híbrido da narrativa. A escritora, por sua vez, declarou pouco se importar com as classificações, alegando que é indiferente ao "gênero" [literário] e que se sente muito à vontade com as diferentes categorizações que seu livro já recebeu (PERNAMBUCO, 2016).

Empreendemos essa discussão inicial com o objetivo de apurar se podemos situar Esse Cabelo no âmbito do que Foucault (2004) chamou de "a escrita de si". Concluímos que sim, pois, de acordo com esse teórico,

[a função-autor] não é definida pela atribuição espontânea de um discurso ao seu produtor, mas por uma série de operações específicas e complexas; ela não remete pura e simplesmente a um indivíduo real, ela 
pode dar lugar simultaneamente a vários egos, a várias posições-sujeito que classes diferentes de indivíduos podem vir a ocupar. (FOUCAULT, 2001, p. 20).

Não se trata, portanto, de comprovarmos que existe identidade taxativa entre Mila e Djaimilia Pereira de Almeida, embora os fatos concretos nos induzam a declarar que a obra é um relato puramente autobiográfico. A possibilidade de estudarmos Esse Cabelo enquanto exercício da escrita de si advém do fato de que a obra constitui uma unidade coerente guiada pela consciência de um ente que não se resume à escritora (como indivíduo físico) ou à narradora-personagem; esse ente é um ego plural, uma função (a "função-autor") que emerge justamente na cisão - na divisão e na distância - entre o escritor real e o locutor fictício. (FOUCAULT, 2001, p. 19). Mila, a protagonista e narradora da história, de qualquer forma jamais poderia ser confundida com a escritora: ela é um alter ego cuja distância pode aumentar ou diminuir em relação à própria Djaimilia. O verdadeiro autor, nessa perspectiva, apresenta-se como foco de expressão, um instrumento que congrega discursos plurais, conferindo-lhes coerência, em relação uns aos outros. Essa assertiva alinha-se às impressões da escritora, que, apesar de reconhecer os traços autobiográficos da obra (ou seja, os pontos em que o produtor físico do discurso e seu alter ego discursivo se aproximam na narrativa), ressalta que os sentidos produzidos são resultado de emoções e inquietações provenientes de diversas fontes - elementos que se reúnem no romance em formato de relato confessional, por meio do qual a protagonista tenciona recuperar sua identidade.

Ademais, não são suas eventuais características autobiográficas que tornam Esse Cabelo um objeto passível de análise sob a ótica do exercício do "relato de si"; afinal, como nos ensina Butler (2015), o mero ato de contar uma história sobre si não é o mesmo que dar um relato de si. Relatamos a nós mesmos quando somos interpelados por um sistema de justiça e castigo que instrumentaliza a violência ética: um tipo de violência oriunda dos anacronismos dos sistemas de moral. Mila reconhece o seu cabelo crespo e sua pele negra como principais marcadores da diferença que a distingue no seio da sua família portuguesa, pela qual foi criada. Nessa toada, a narradora-protagonista empreende uma longa discussão acerca da construção da sua identidade, em um contexto no qual fica evidente o caráter fragmentário de uma cultura pós-colonial, que reverbera todas as consequências da diáspora africana.

Trabalharemos a hipótese de que o corpo, enquanto ferramenta política de compreensão do mundo, pode ser objeto da violência descrita por Butler, à medida que também se submete às pretensões morais da universalidade - "uma universalidade que deixa de responder à particularidade cultural e não reformula a si mesma em resposta às condições sociais e culturais" (BUTLER, 2015, p. 10). Para Butler, a história do "eu” é a história de uma relação ou conjunto de relações para com o conjunto de normas, e dar um relato de si mesmo é se apropriar da moral corrente, justificando-se perante ela. Em Esse Cabelo, a personagem principal demonstra toda a sua angústia diante de um sistema de regras postas, que a estimulam a obedecer um 
padrão universal de moral e de estética, mas existem variáveis incontornáveis - o cabelo, a pele, o corpo, em resumo - que a impedem de se entregar ao que Butler chama de "uma apropriação vital”. É desse conflito entre o universal e o individual que surge a violência ética, já que o éthos coletivo instrumentaliza essa violência para manter sua aparência de coletividade, num anacronismo que exclui a diversidade e mascara a complexidade das relações que se estabeleceram a partir da multiculturalidade. Assim, na obra a ser analisada, consideramos que o cabelo (a "diferença") funciona como o agente interpelador que instiga a personagem a dar um relato de si mesma, diante das condições sociais, históricas e morais em que ela se reconheceu e se constituiu como sujeito.

\section{ESSE CABELO: SÍNTESE E DISCUSSÕES PRELIMINARES}

O romance Esse Cabelo, de Djaimilia Pereira de Almeida, é uma narrativa em primeira pessoa conduzida por uma jovem apresentada como Mila, que logo de início revela a intenção de fazer uma "biografia do seu cabelo". A personagem parece reconhecer uma certa futilidade intrínseca ao tema, para em seguida ressaltar que seu cabelo crespo e seco constitui uma geopolítica, uma vez que perpassa a história de pelo menos dois países (Portugal e Angola) e que representa a relação entre vários continentes. Mila revela de antemão que foi submetida a variados sofrimentos físicos por conta do cabelo, em salóes de beleza onde se entregou à "aprendizagem da feminilidade" (ALMEIDA, 2015, p. 15).

Mila considera que é imprescindível resgatar a história de seus ancestrais, de quem herdou o cabelo e diversos traços identitários, para tecer essa biografia. Em suas palavras, "saber de onde venho, no entanto, pareceria crucial para a história do meu cabelo" (ALMEIDA, 2015, p. 34). Conta que seus familiares, durante quatro gerações, descreveram o caminho entre Portugal e Angola, que foi colônia lusitana até 1975. Compreendemos que a identidade nacional da família é muito fragmentária: a avó materna era filha de um comerciante português e de sua esposa igualmente portuguesa - nasceu no Congo, porém foi criada na Europa; o avô paterno era um engenheiro que se mudou para Angola depois do casamento, para trabalhar; o pai, por isso, passou a juventude em Angola, onde se casou com uma jovem nativa; os avós maternos, embora angolanos, mudaram-se para Portugal, para o tratamento da saúde de um dos filhos. Mila, nascida em Angola, de pai branco e mãe negra, transferiu-se para Portugal com apenas três anos de idade. Passou a infância na casa dos avós paternos, nos arredores de Lisboa.

Uma das primeiras figuras que ganham destaque na narrativa é Castro Pinto, o "avô negro", ou "Papá". Formado enfermeiro em Angola, viajou para Portugal com o filho em 1984, por conta da grave enfermidade deste último: uma das pernas, nascida mais curta que a outra, exigia cuidados não disponíveis na terra natal. Nessa passagem, a obra se coloca como crítica às condições de decrepitude a que são submetidos os africanos na Europa, abrigados em pensões nas proximidades dos hospitais. Mila chama esses enfermos de "despojos do 
império" (ALMEIDA, 2015, p. 20), o que nos remete à diáspora africana e às consequências do colonialismo.

Entrar na Covilhã é meter o nariz numa mala velha. A pensão tem não o aroma alcóolico que se sente nos hospitais, mas o cheiro a unguentos expirados combinado com o odor a podre das infecções e uma vaga nota metálica a sangue, traços de naftalina, numa mistura ao mesmo tempo química e orgânica, cortada por um traço adocicado de ketchup ou Old Spice, vertidos dos frascos para a mala por entre fios de cabelo e tintura de iodo, e inutilizando uma embalagem de Valium. O meu avô adormece neste cheiro com uma resignação cabal, perguntando ao meu tio se o quarto não lhe cheira a mulher. (...) A Covilhã sobrelotada não é, em Lisboa, uma estalagem de vila, mas uma colônia de leprosos à beira da estrada, ao mesmo tempo no centro da cidade e ostracizada, porque para chegarmos a nenhures basta virar uma esquina suja. (...) Muitas vezes, os doentes passam ali anos, tendo da cidade apenas um vislusmbre, e do país somente o conceito de "chanfana" (...) (ALMEIDA, 2015, p. 21-22).

Depois de dez anos na pensão precária, Castro Pinto mudou-se para um bairro clandestino nos arredores da cidade, mandando virem de Angola a esposa e outros filhos, passando a viver "numa casa que também cheirava a mala velha". (ALMEIDA, 2015, p. 23).

Mila segue a biografia do seu cabelo relatando experiências de infância e juventude: a primeira ida ao salão de beleza, as conversas na casa da avó portuguesa, a descoberta da sexualidade, os passeios pela cidade com a mãe angolana, as longas horas de "tortura" durante as quais cabelereiras esticavam seu cabelo e o embebiam com substâncias químicas urticantes, não sem alguma brutalidade e comentários depreciativos. No decorrer do romance, compreendemos que Mila sofre de uma permanente frustração por não se reconhecer enquanto estereótipo: apesar de se considerar portuguesa e de manter uma relação bem mais distanciada com sua família africana, o cabelo crespo apresenta-se como um problema permanente, um lembrete da sua diferença, um incômodo que lhe causa sofrimento físico, psicológico e moral. A narradora ressente-se da noção caricaturada de nacionalidade; para ela, o cabelo é um marcador estético da desilusão.

A minha avó branca (de que forma dizê-lo sem soar a novela brasileira?) perguntava-me pelo cabelo: "Então, Mila, quando é que tratas esse cabelo?” O cabelo era então distintamente uma personagem, um alter ego presente na sala. (ALMEIDA, 2015, p. 45).

Mila aceita o rótulo de angolana falsa, ao tempo em que se recusa a pensar em si mesma a partir de um estereótipo (ALMEIDA, 2015, p. 33-34). A sua identificação com a família portuguesa é premente; tão naturalizada que, segundo ela, durante boa parte da vida sequer soube 
que possuía um cabelo, e que esse cabelo poderia ter uma história. Ademais, ela identifica seu descuido com os cachos como um sinal de que Portugal é a sua casa - como pista de que sua identificação pessoal a fazia esquecer do marcador que a distinguia fisicamente do resto da sua família nuclear. Descobriu o cabelo por conta dos sucessivos esforços empreendidos por terceiros para controlá-lo, roubar-lhe a natureza crespa, sentindo-se, ela mesma, como objeto de controle.

Inconformada com o estado do meu cabelo, agarrou num secador e numa escova e, no intervalo de pentear a minha avó, esticou duas madeixas por caridade, para provar que não era um caso perdido. "Está a ver? Não lhe digo que a Mila tem um belo cabelo? É só esticar um bocadinho e - veja!" (...) Eu nascia, com um grau distinto de paranoia, para o meu cabelo e ao mesmo tempo para uma ideia de mulher. (ALMEIDA, 2015, p. 28)

A custódia partilhada do meu cabelo exprime uma condição humana que as nossas birras de adultos tentam escamotear. Talvez eu deva dizer que é assim desde que somos pequenos, que a vida se parece com a sustentação contínua de um interregno de passividade, durante o qual nos fazemos gente. (ALMEIDA, 2015, p. 50).

Ao sentimento de confusão no resgaste da identidade, adiciona-se uma certa culpa pelo distanciamento em relação a Angola, pelo desconhecimento da África. Mila mantinha uma relação de desconforto com a mãe, sentindo-se constrangida durante os fugazes passeios pelas ruas de Lisboa ou deslocada durante as viagens de férias para Luanda. Angola aparece-lhe como déjà-vu; o processo de reconstrução da história do cabelo, talvez mesmo por isso, é reconhecido por Mila como o acompanhamento da reconstrução da própria Luanda. Com a avó portuguesa, paralelamente, os laços de identificação carregam maiores afetos: a narradora invejava as primas que haviam herdado o cabelo de Lúcia, sendo este uma bênção, "uma herança viva e vã". (ALMEIDA, 2015, p. 33). O cheiro dos cabelos da avó paterna, para Mila, foi o primeiro lugar em que julgou ter origem, tudo que ela poderia dizer sobre sua identidade: o cabelo de Lúcia era sua pátria.

Entre laços, vivências, penteados dolorosos, desapontamento e deslocamento, surge a noção de uma estética preconceituosa, transmutada em moral. Mila se sente constantemente julgada por um sistema que lhe é estranho, no qual impera a violência ética descrita por Butler (2015). É com foco nessa categoria que prosseguiremos a análise de Esse Cabelo enquanto um relato de si. 


\section{3. ÉTICA E ESTÉTICA: O CORPO COMO ALVO DA VIOLÊNCIA DA MORAL}

No tópico anterior, entrevimos que o relato de Mila, ou a biografia de seu cabelo crespo, é permeado por manifestações de culpa e frustração. Sua juba revolta, todos os dias, apresenta-se como motivo de vergonha ou de troça, o que gera impaciência e, às vezes, raiva. Chama atenção o fato de que a narradora frequentemente atribui a si mesma a "culpa" pelas características do cabelo que considera desfavoráveis, usando diversas vezes vocábulos como "descuido" e "desmazelo". Ela parece se condenar também por dar importância a um assunto aparentemente "frívolo", colocando sua preocupação e seu incômodo com o cabelo no nível do "supérfluo". Mila chega a declarar que o domínio da beleza invade o domínio da ética, já que suas frustrações estéticas se transmutam em falha moral, em maldição.

O meu desapontamento com o cabelo acompanhou-me ao longo de uma transmutação, de um prurido insignificante até uma urticária abrasiva: a transmutação da estética em moralidade, do secador em juiz, da falta de jeito em fatalismo, do penteado abortado em culpa, danação - da cabeleireira bruta em psicose. Fazer as pazes conosco parece-se, penso para comigo, com fazer as pazes com nossa ascendência, como se estarmos bem na nossa pele adviesse do apaziguamento de termos uma família. (ALMEIDA, 2015, p. 51-52).

Por conta dessa confusão entre domínios, elemento que tanto perturba Mila e fragmenta sua identidade, a leitura de Esse Cabelo propicia reflexões acerca da moral e da ética da estética no contexto das pretensões de universalidade. A obra se apresenta como um relato de si à medida que o cabelo funciona com um agente interpelador que força a personagem a discorrer sobre sua identidade.

Consideramos que Mila está inserida em uma situação de violência ética. Butler (2015) explica que essa violência ocorre quando a moral dominante, tencionando continuar sendo compreendida como "universal", sufoca as dimensões individuais e mascara os anacronismos. Um sistema de moral torna-se anacrônico quando sua apropriação vital, por parte dos indivíduos, torna-se impossível. O éthos coletivo, porém, tende a reafirmar sua aparência de coletividade, tornando-se violento. Ocorre que, diante da tendência à recalcitrância desses sistemas, existem contextos sociais mutáveis, sujeitos a diversas variáveis históricas e culturais.

Em Esse Cabelo, deparamo-nos com um padrão estético naturalizado, europeizado, para o qual os cabelos lisos integram a ordem das coisas. Para a protagonista, esse padrão estético converteu-se em padrão moral, e, como tal, foi atingido pelo anacronismo: num cenário em que entram em jogo os efeitos da colonização e das independências, dos fluxos migratórias e da diáspora africana, as antigas normas de conduta tornam-se inaplicáveis, por conta das novas populações que transitam pela Europa. Os sistemas resistem, porém, gerando angústia e sofrimento. Para Mila, é virtualmente impossível apropriar-se do padrão estético atrelado à 
família com a qual se identifica, já que a cor de sua pele e a textura de seu cabelo são características biologicamente incontornáveis. A tentativa de adaptá-los ao sistema falsamente universal, à custa de procedimentos violentos, só produz frustração, culpa e fragmentação identitária.

Se uma apropriação vital é impossível, parece então seguir-se que o preceito só pode ser experimentado como uma coisa mortal, um sofrimento imposto, de um exterior indiferente, à custa da liberdade e da particularidade. (BUTLER, 2015, p. 10).

Nesse ponto, percebemos que o corpo, ao ser parametrizado por meio de uma determinada estética, pode ser objeto da violência ética, à medida em que a estética se converte em moral com pretensões universalizantes. O corpo se torna vítima da violência ética ao passo em que se revelam os conflitos entre as características individuais - ou os marcadores de diferença, como um cabelo crespo - e aquilo que é universalmente admitido como belo e aceitável, em determinada comunidade. No âmbito dessa violência, está inscrita a "má consciência": "O 'eu' volta-se contra si mesmo, desencadeando contra si mesmo uma agressão moralmente condenatória, e com isso, inaugura-se a reflexividade”. (BUTLER, 2015, p.11).

Encontramos aqui uma possível explicação para a culpa repetidamente expressa pela personagem Mila, em seu relato de si mesma. Incapaz de igualar-se ao que ela mesma considera ideal - por força da identificação e do afeto com a sua avó Lúcia - Mila se sente interpelada, pelo sistema moral de justiça e castigo, a justificar-se, a questionar a ancestralidade do seu cabelo, construindo a partir dele um retrato de sua formação enquanto sujeito inserto no sistema de normas. A "biografia do cabelo" é uma história do "eu", e a história do "eu", por sua vez, é também a história de uma relação do indivíduo para com um conjunto de regras. (BUTLER, 2015, p. 11). Para Mila, o retrato de sua vida é o retrato de uma autoperseguição e da tentativa diária de lhe ser indiferente. (ALMEIDA, 2015, p. 103). Ainda segundo Butler (2015), o "relato de si" é um instrumento de que lançamos mão quando alguém nos pede, a partir da acusação de que causamos sofrimento aos outros, ou, pela má consciência, a nós mesmos.

Nitzsche acertou muito bem quando disse que só começamos a contar uma história de nós mesmos frente a um "tu" que nos pede que o façamos. É somente frente a essa pergunta ou atribuição do outro - "Foste tu?" - que fornecemos uma narrativa de nós mesmos ou descobrimos que, por razões urgentes, devemos nos tornar seres autonarrativos. (BUTLER, 2015, p. 13).

A esse momento em que o "tu" nos questiona, Butler chama de "cena de interpelação". É a interpelação que motiva o relato; é a alegação da culpa que baseia as justificativas. Depois de concluirmos que a narrativa de Esse Cabelo se desdobra num cenário de violência ética direcionada ao corpo, podemos empreender a identificação dos elementos que constituem o relato de Mila: o "tu" interpelador, a culpa autoatribuída, o medo da punição. Em diversos 
momentos do romance, a narradora se refere ao próprio cabelo como um ente autônomo, dotado de vida própria. Mila é diferente, e o fator que a lembra constantemente da sua diferença é o cabelo: o cabelo crespo é uma exclamação, um demarcador. Desse modo, podemos situá-lo como agente interpelador, a força motriz do relato. É o desconforto causado pelo cabelo que coloca a personagem em posição de reflexividade. Vejamos:

Não posso é esquecer-me deste cabelo sem me esquecer também de mim e seguir à minha frente deixando-me para trás como duas pessoas que se perdem numa feira, admiti para comigo mais tarde. Na sequência desse último corte começaria a vontade de saber a sua história. (ALMEIDA, 2015, p. 86).

Já a culpa abordada no relato se manifesta nas sucessivas tentativas de esquecimento do cabelo, na vergonha que Mila demonstra sentir de si mesma, na impossibilidade de superar as diferenças que a separam de sua família mesmo depois de tantos alisamentos e penteados, realizados à custa de muita violência - nesse caso, física, e não propriamente ética. A violência ética consistirá na autocondenação imposta após a frustração com o insucesso das empreitadas.

O medo da punição, por sua vez, advém do repúdio que o sistema de normas expressa contra aquela característica particular que não está incluída no espectro dos padrões universalmente aceitos. Esse repúdio se traduz nas práticas segregacionistas, nas censuras dirigidas ao cabelo de Mila.

O meu pai levava-me a andar de pônei e eu afectava umas vertigens. Espelhos mágicos mostravam-me como eu seria um dia, uma repetição maravilhosa que me consolava. Foi num desses passeios que nos abordaram numa rua de Lisboa, em que seguíamos de mãos dadas, perguntando se éramos da mesma família, eu e o meu pai, com uma curiosidade abominável. (ALMEIDA, 2015, p. 66).

Há outros trechos em que a narradora descreve situações de preconceito que viveu, em diferentes contextos. É por meio do relato de si mesma que Mila pretende livrar-se do pavor do escamoteamento social, ao identificar ancestralidades, descobrir que viveu sob a sombra de uma confusão doméstica entre afeto e preconceito e ainda negar os estereótipos nacionais.

\section{CONSIDERAÇÕES FINAIS}

Esse cabelo é uma obra que se apresenta como relato biográfico em primeira pessoa, constituindo-se como relato de si à medida que representa a relação do sujeito com um conjunto de normas sociais - nesse caso, as normas estéticas, que, justamente pelo caráter coercitivo que assumem, transmutam-se em moral anacrônica. Não se trata de comprovarmos 
que a narrativa tem condão autobiográfico, no que se refere à escritora Djaimilia Pereira de Almeida, inobstante as justaposições entre a história pessoal desta e a da personagem Mila - até porque vimos que a função-autor não se limita ao artista enquanto pessoa física ou ao locutor fictício, mas que reside exatamente nas cisões e aproximações entre esses dois egos, de modo a constituir um foco narrativo. Optamos por conduzir uma análise do ponto de vista interno à trama, já que todo o romance se baseia em movimentos de reflexividade, a partir de uma cena de interpelação, que é o reconhecimento do cabelo enquanto fator de diferenciação individual.

Os sistemas de normas reconhecidos na obra, além dos padrões estéticos, consubstanciam-se nos estereótipos nacionais, que estabelecem uma série de regras identitárias. Contudo, num mundo em que as identidades estão em trânsito constante, lidando com o apagamento e a diluição das fronteiras, tais modelos tornam-se cada vez mais distantes dos indivíduos, o que atesta o anacronismo do sistema. À medida em que se torna impossível a apropriação vital das normas pretensamente universais de conduta, mais o indivíduo se torna suscetível ao sofrimento, à angústia e à autocondenação. Não é de Mila, tampouco de seu cabelo, a culpa pela sensação de deslocamento que aflige a personagem: é da resistência universalizante da moral estética, que não se predispõe a passar por uma revisão crítica e admitir que a sociedade atual comporta identidades mutáveis, não estanques, líquidas.

Fizemos um estudo centralizado na narradora, admitindo que essa entidade fictícia faz um relato de si mesma na trama interna do romance. Sabemos que a literatura, embora não reflita a realidade fidedignamente, tem a propriedade de a refratar, funcionando como instrumento do plasmar de uma era, de um sistema, dos sentimentos que ressoam na interioridade dos indivíduos. Desse modo, acreditamos que Esse Cabelo pode nos dar pistas valiosas acerca da relação entre a negritude e a moral estética vigente, ajudando-nos a compreender como corpos negros e cabelos crespos podem ser vítimas de violência ética, e chamando a atenção para a necessidade da revisão crítica dos sistemas de normas que incidem sobre o corpo.

\section{REFERÊNCIAS}

ALMEIDA, D. P. de. Esse cabelo: a tragicomédia de um cabelo crespo que cruza a história de Portugal e Angola. Alfragide: Teorema, 2015.

BUTLER, J. Relatar a si mesmo: crítica da violência ética. Belo Horizonte: Autêntica, 2015.

FOUCAULT, M. A escrita de si. In: Ética, sexualidade, política. Rio de Janeiro: Forense Universitária, 2004. p. 144-162. Disponível em: <http://historiacultural.mpbnet.com.br/posmodernismo/Foucault-A_escrita_de_si.pdf>. Acesso em 07 ago. 2019.

FOUCAULT, M. O que é um autor? In: Ditos e Escritos: Estética - literatura e pintura, música e cinema (vol. III). Rio de Janeiro: Forense Universitária, 2001. p. 264-298. Disponível em: 
$<$ https://edisciplinas.usp.br/pluginfile.php/179076/mod_resource/content/1/Foucault Michel - O que é um autor.pdf $>$. Acesso em 13 ago. 2019.

PERNAMBUCO - Suplemento Cultural do Diário Oficial do Estado. [Entrevista] Djaimilia Pereira de Almeida. Editoria Entrevistas, 30 de setembro de 2016. Disponível em: $<\mathrm{https}: / / \mathrm{www}$. suplementopernambuco.com.br/entrevistas/1694-entrevista-djaimilia-pereira-de-almeida. html>. Acesso em 27 jul. 2019.

REDE ANGOLANA. Djaimilia Pereira de Almeida. Editoria Cultura, o7 de setembro de 2015. Disponível em: <http://www.redeangola.info/especiais/85033-2/>. Acesso em 05 ago. 2019.

Recebido para publicação em 18 de Dezembro de 2019. Aceito para publicação em 28 de Janeiro de 2020. 